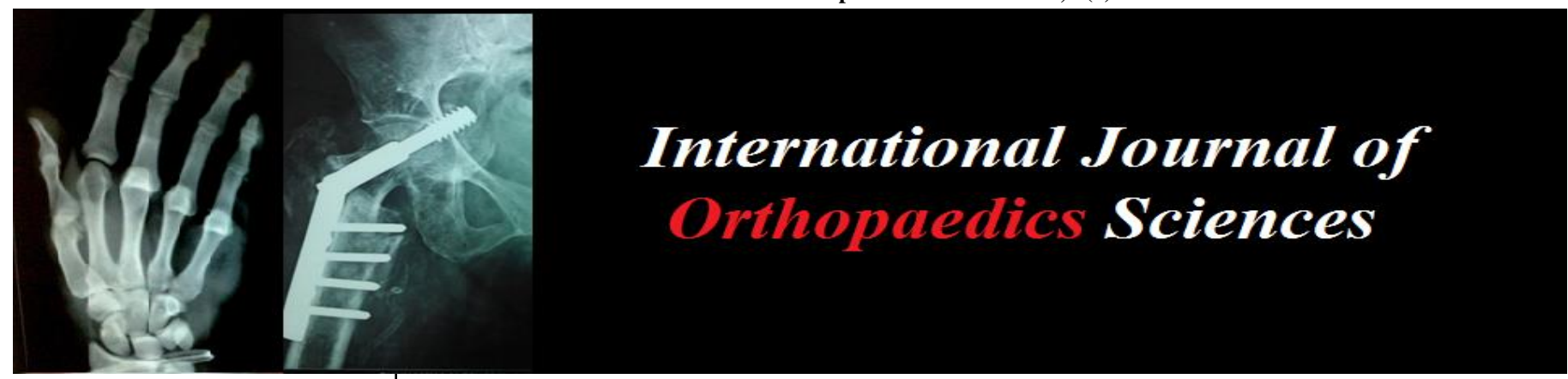

E-ISSN: 2395-1958

P-ISSN: 2706-6630

IJOS 2021; 7(3): 870-872

(C) 2021 IJOS

www.orthopaper.com

Received: 04-05-2021

Accepted: 06-06-2021

Saurabh Chaudhary

Associate Professor,

Netaji Subhas Medical College and Hospital, Patna, Bihar,

India

\section{Effect of age of starting ponseti casts and initial pirani score on the number of casts in ponseti treatment of idiopathic clubfoot in infants}

\section{Saurabh Chaudhary}

DOI: https://doi.org/10.22271/ortho.2021.v7.i3m.2847

\section{Abstract}

Purpose: We chose to assess if starting treatment of Clubfoot with Ponseti casts in neonatal or early infancy can reduce the number of casts required for full correction of the feet. We also analysed the relationship between Pirani scores at commencement of treatment and the number of casts required for correction of the deformity.

Methods: Inclusion criteria were idiopathic clubfeet corrected by Ponseti method in children up to one year of age. Children with postural, non-idiopathic, previously surgically treated, recurrent clubfoot were not included in this study. ANOVA regression analysis was used for finding correlation between initial Pirani score, age in weeks and number of corrective casts prior to putting on foot abduction brace.

Results: There were a total of 53 children $(72$ feet) in the study. The average age of the child at presentation was 12 weeks and the average initial Pirani score was 3.4. The average number of corrective casts was six per child (range, 3 to 8). The regression analysis showed both Pirani and age had positive correlation with number of casts, although weak $(\mathrm{r} 2=0.05-0.20)$. The initial Pirani scoring correlated ten times more than age (in weeks) to the number of casts.

Conclusion: The number of casts for correction in idiopathic clubfoot treated in infancy is influenced by both initial Pirani score and age of commencing plasters.

Keywords: idiopathic clubfoot, ponseti method, pirani score, age

\section{Introduction}

The Pirani score is one of the popular systems for classification of severity in clubfoot ${ }^{[1]}$. The initial Pirani scores have been investigated for correlation to the number of casts required for clubfoot correction with variable results ${ }^{[1-5]}$. In tertiary care settings where in house Obstetric and Pediatric services are robust, children often come as early as the date of birth for consultation with the Orthopaedic surgeon. Often times, they are unreceptive to the idea of early cast application as common perception among the society is that the children need to be older and chubbier for plaster application. We often saw that children at younger ages of few weeks to few months had a much more flexible feet amenable to rapid progress in correction of severity scores and often lesser number of plaster casts needed for complete correction. In many instances, children had their plaster correction stage completed by the time they turned a month old. While on the other hand, there were older infants who not only made casting difficult, but also needed more casts, often broke them as they made incessant attempts to crawl and stand in them. We often thought of studying whether age at beginning influences the number of corrective casts. This still remains a topic of interest ${ }^{[6]}$. Lack of data on these subset of younger children made it difficult to explain to parents about the need for starting intervention as early as reasonably possible.

We retrospectively investigated how the number of casts required for deformity correction differed with (a) the age of the child at initial presentation and (b) pre-treatment Pirani score. Further, did a correlation exist between them, if any?

\section{Material and methods}

We retrospectively analysed the records of enrolled children with primary idiopathic clubfoot managed in a Clubfoot Clinic at Netaji Subhash Medical College and Hospital which is a

\footnotetext{
Corresponding Author: Associate Professor, Netaji Subhas Medical College and Hospital, Patna, Bihar, India
} 
tertiary care private hospital attached to a medical college in a metropolitan city in eastern India. Study was conducted between August 2019 to June 2020. The clinic followed protocols based on Ponseti technique [7]. A standardized proforma was used to collect patient specific data and scores during the course of follow up of each patient in clinics following enrolment in the Clubfoot Clinic. The data sheet contained the demographic data of the patient, the type of clubfoot, Pirani scores at presentation and during follow ups, number of corrective casts for each patient, timing of tenotomy and follow up after foot abduction brace ${ }^{[7]}$.

Children with postural, non-idiopathic (neuromuscular, syndromic, complex and others), surgical treatment in any form, age greater than one year, recurrent clubfoot and defaulters (noncompliance with serial casting schedule) were not included in this study. Further, children who did not require tenotomy were also excluded. The number of casts prior to tenotomy was used for result evaluation. The same team was responsible for care of all the patients.

\section{Statistical analysis}

We adopted the following statistical methods to analyse the data:

1. The correlation between pre-treatment Pirani score, child's age in months at presentation and number of corrective casts was calculated after doing the ANOVA regression analysis.

2. ANOVA multiple regression analysis was applied to develop a combined mathematical equation to calculate the number of corrective casts from Pirani score (at initial presentation) and age (in weeks at the time of presentation) for the child.

3. Coefficient of determination (r2) was calculated for each equation.

\section{Results}

There were a total of 53 children ( 72 feet) that met the inclusion criteria. Of these, 14 children presented with left sided, 18 right sided and 21 bilateral cases. The male-female ratio in the study was nearly $3: 1$ with 38 males and 15 females. The average age of the child at commencement of casts was 10.3 weeks (range, 0 weeks to 50 weeks).

The average pre-treatment Pirani score was 4.8 (range, one to six). The average number of corrective casts was seven per child (range, two to 8). The average number of corrective casts required for the different age.

The regression analysis further suggests that the number of corrective casts required till tenotomy increases with age. There was an average increase of one cast for every increase in age of 20 months (Eq. 2). It shows that the effect of initial Pirani score (severity of deformity) on the total number of casts is approximately ten times stronger for number of casts when compared to age in months.

The correlation was stronger when both Pirani scoring and age were considered $(\mathrm{r} 2=0.20)$. Children younger than six months and presenting with Pirani scores between 3 and 6 , the average casts will be approximately four and eight, respectively.

\section{Discussion}

The Ponseti method has become the gold standard for clubfoot treatment ${ }^{[8]}$. Several short-term and long-term results of the Ponseti method in the treatment of idiopathic club foot are now available $[9,10]$. Pirani scores have been frequently used to track treatment progress [11], predict tenotomy requirements ${ }^{[1,4,12,13]}$, number of casts of treatment [6] and relapse rates ${ }^{[14]}$. However, a question which is commonly posed by parents at time of initial counselling is the number of casts their child will require, especially when the child is older and walking. This assumes greater importance in developing countries where the duration of treatment has a strong bearing on parent's compliance and success of treatment. Conflicting reports are present in literature regarding use of Pirani score and its predictive value for number of casts for correction. Dyer and Davis reported on predictive value of Pirani scoring on 70 idiopathic club feet ${ }^{[1]}$. They found a positive correlation $(r=0.72)$ between initial Pirani score and number of casts required to correct the deformity. A foot scoring of 4 or more is likely to require at least four casts, and one scoring less than 4 will require three or fewer ${ }^{[1]}$. There was no linear relationship between initial Pirani scores and number of corrective casts in this study. In another study by Chu et al. (185 feet; mean age 15.3 days), the mean number of casts required were $5.1^{[2]}$. The average Pirani scores versus number of casts were $2 / 2,4 / 3,5 / 4,5.5 / 5$, $5.5 / 6,5.5 / 7$, and 6/8. The initial Pirani scores correlated poorly $(r=0.33)$ with number of casts required for clubfoot correction ${ }^{[2]}$. In a study on the use of Ponseti method in clubfoot in toddlers, the number of casts in younger children was less compared to older children (one to two years, six to ten casts; two to three years, nine to12 casts) ${ }^{[15]}$. With older children, the casts showed a trend to increase. In a series by Khan and Kumar, in children with mean age 8.9 years, the average number of casts were $12.1^{[16]}$. In a contradiction to above findings, Spiegel et al. used the Ponseti method for children aged one to six years $(n=260){ }^{[17]}$. They found no differences in the number of casts required when comparing the different age groups or initial Pirani scores (age one year: Pirani 5.15, no. of casts six; two years: Pirani 5.23, no. of casts six; three years: Pirani 5.55, no. of casts seven; four years: Pirani 4.86, no. of casts seven; five years: Pirani 4.55 , no. of casts seven) ${ }^{[17]}$. There is another study supporting this finding in younger children by Alves et al. where the number of casts required was 5.3 and 4.3 when mean age at beginning of treatment was 22.4 days and 402.8 days, respectively ${ }^{[6]}$.

Our study confirmed the weak but positive correlation between initial Pirani score and age on the number of corrective casts (see equations above) ${ }^{[15,17-19]}$. The Pirani scoring was ten times more predictable for number of casts when compared to age. The correlation was more useful when both Pirani scoring and age were taken into account ( $\mathrm{r} 2=0.20)$. Thus, the foot correction is probably also affected by other factors beyond Pirani scoring and age. There were several limitations of this study. It is a retrospective study with a heterogeneous (age and Pirani variable) group under study. The study excluded clubfeet not requiring tenotomy as these possibly form another cohort with suppler soft tissues correctable by casts. Several authors have reported the decreased significance of Pirani scoring in the older child [17, 20]. The long-term follow up was not available to ascertain whether the initial correction obtained could be maintained. The present series had 52/442 $(11.76 \%)$ feet beyond two years achieving initial correction using Ponseti method, and this is encouraging. The study thus indirectly reemphasizes the effectiveness of the Ponseti method in both younger and older age groups and it's usefulness in developing countries $[16,17$, ${ }^{20]}$. Although parents may be given an estimate about the average number of cast at counselling, they need to be reemphasized that number of casts is highly variable. 


\section{References}

1. Dyer PJ, Davis N. The role of the Pirani scoring system in the management of clubfoot by the Ponseti method. J Bone Joint Surg [Br] 2006;88-B:1082-1084.

2. Chu A, Labar AS, Sala DA, van Bosse HJP, Lehman WB. Clubfoot classification: correlation with Ponseti cast treatment. J Pediatr Orthop 2010;30:695-699.

3. Dobbs MB, Rudzki JR, Purcell DB et al. Factors predictive of outcome after use of the Ponseti method for the treatment of idiopathic clubfeet. J Bone Joint Surg [Am] 2004;86-A:22-27.

4. Scher DM, Feldman DS, Van Bosse HJ, Sala DA, Lehman WB. Predicting the need for tenotomy in the Ponseti method for correction of clubfeet. J Pediatr Orthop 2004;24:349-352.

5. Haft GF, Walker CG, Crawford HA. Early clubfoot recurrence after use of the Ponseti method in a New Zealand population. J Bone Joint Surg [Am] 2007;89A:487-493.

6. Alves C, Escalda C, Fernandes P, Tavares D, Neves MC. Ponseti method: does age at the beginning of treatment make a difference? Clin Orthop Relat Res 2009;467:1271-1277.

7. Staheli L. Clubfoot: Ponseti management. Global-HELP Publication 2003.

8. Radler C. The Ponseti method for the treatment of congenital club foot: review of the current literature and treatment recommendations. Int Orthop 2013;37:17471753.

9. Oštádal M, Chomiak J, Dungl P, Frydrychová M, Burian M. Comparison of the short-term and long-term results of the Ponseti method in the treatment of idiopathic pes equinovarus. Int Orthop 2013;37:1821-1825.

10. Radler C, Mindler GT, Riedl K, Lipkowski C, Kranzl A. Midterm results of the Ponseti method in the treatment of congenital clubfoot. Int Orthop 2013;37:1827-1831.

11. Hegazy M, Nasef NM, Abdel-Ghani H. Results of treatment of idiopathic clubfoot in older infants using the Ponseti method: A preliminary report. J Pediatr Orthop B 2009;18:76-78.

12. Bor N, Coplan JA, Herzenberg JE. Ponseti treatment for idiopathic clubfoot: minimum 5-year follow up. Clin Orthop Relat Res 2009;467:1263-1270.

13. Bor N, Herzenberg JE, Frick SL. Ponseti management of clubfoot in older infants. Clin Orthop Relat Res 2006;444:224-228.

14. Goriainov V, Judd J, Uglow M. Does the Pirani score predict relapse in clubfoot? J Child Orthop 2010;4:439444.

15. Verma A, Mehtani A, Sural S, Maini L, Gautam VK, Basran SS et al. Management of idiopathic clubfoot in toddlers by Ponseti's method. J Pediatr Orthop B 2012;21:79-84.

16. Khan SA, Kumar A. Ponseti's manipulation in neglected clubfoot in children more than 7 years of age: A prospective evaluation of 25 feet with long-term followup. J Pediatr Orthop B 2010;19:385-389.

17. Spiegel DA, Shrestha OP, Sitoula P, Rajbhandary T, Bijukachhe B, Banskota AK. Ponseti method for untreated idiopathic clubfeet in Nepalese patients from 1 to 6 years of age. Clin Orthop Relat Res 2009;467:11641170

18. Yagmurlu MF, Ermis MN, Akdeniz HE, Kesin E, Karakas ES. Ponseti management of clubfoot after walking age. Pediatr Int 2011;53:85-89.
19. Adegbehingbe OO, Oginni LM, Ogundele OJ, Ariyibi AL, Abiola PO, Ojo OD. Ponseti clubfoot management: Changing surgical trends in Nigeria. Iowa Orthop $\mathbf{J}$ 2010;30:7-14.

20. Lourenço AF, Morcuende JA Correction of neglected idiopathic club foot by the Ponseti method. J Bone Joint Surg Br 2007;89-B:378-381. 